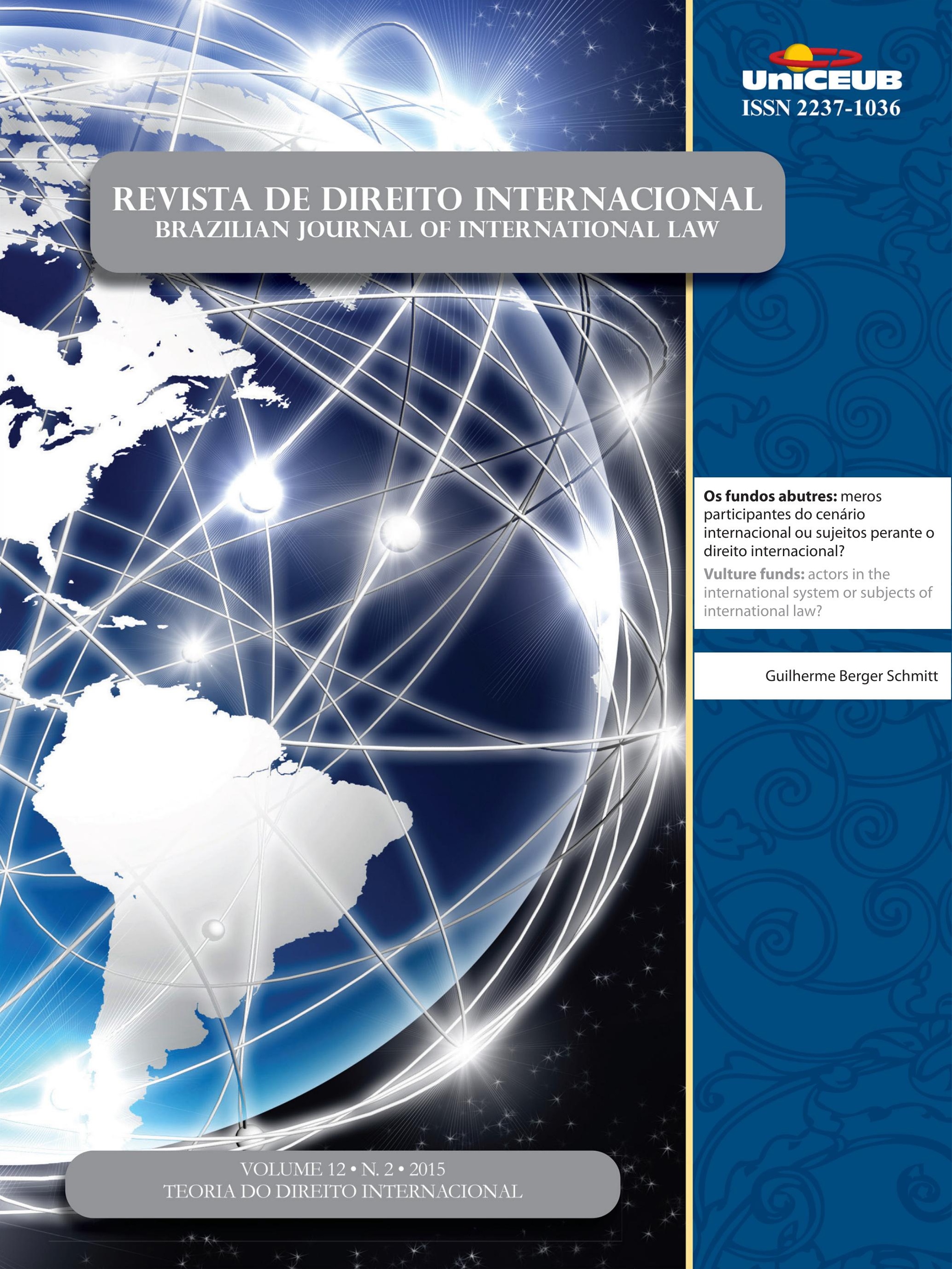




\section{Sumário}

CrôNiCAS DA ATUALIDADE do DiREITo INTERnACIONAL ..................................................... 2 Sarah Dayanna Lacerda Martins Lima, Carina Costa de Oliveira e Erika Braga

CrôniCas do Direito InternaCional dos InVESTIMENTOS ..............................................12 Nitish Monebhurrun

Por que voltar a Kelsen, o jurista do século XX ? 16 Inocêncio Mártires Coelho

O Princípio da Efetividade como conteúdo da norma fundamental (GrundNorm) DE KELSEN

Carlos Alberto Simões de Tomaz e Renata Mantovani de Lima

A JURIDIFICAÇÃo DE CONFLITOS POLÍTICOS NO DIREITO INTERNACIONAL PÚBLICO CONTEMPORÂ-

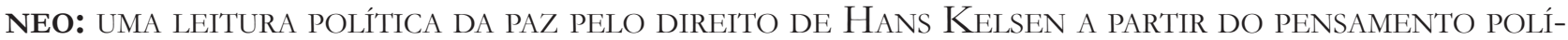
TICO De Claude Lefort

Arthur Roberto Capella Giannattasio

O SINCRETISMO TEÓRICO NA APROPRIAÇÃO DAS TEORIAS MONISTA E DUALISTA E SUA QUESTIONÁVEL UTILIDADE COMO CRITÉRIO PARA A CLASSIFICAÇÃO DO MODELO BRASILEIRO DE INCORPORA-

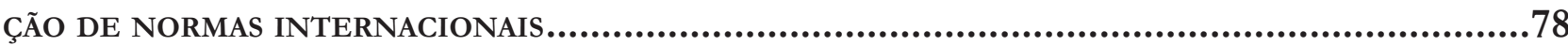
Breno Baía Magalhães

Direito Global em Pedaços: Fragmentação, Regimes e Pluralismo .98 Salem Hikmat Nasser

Por uma TeOria JURÍdica da INTEGRaÇão REgIONAL: A INTER-RELAÇÃO DiREITO INTERNO, DiREITO INTERNACIONAL PÚBLICO E DIREITO DA INTEGRAÇÃO Jamile Bergamaschine Mata Diz e Augusto Jaeger Júnior

A teOria DA INTERCONSTITUCIONALIDADE: UMA ANÁlISE COM BASE NA AMÉRICA LATINA...........160 Daniela Menengoti Ribeiro e Malu Romancini 
O DIÁLOGO HERMENÊUTICO E A PERGUNTA ADEQUADA À APLICAÇÃo DOS TRATADOS INTERNACIONAIS DE DIREITOS HUMANOS NO BRASIL: CAMINHOS PARA O PROCESSO DE INTERNACIONALIZAÇÃO

DA CONSTITUIÇÃO...................................................................................... 176

Rafael Fonseca Ferreira e Celine Barreto Anadon

O DIREITO COMPARADO NO STF: INTERNACIONALIZAÇÃO DA JURISDIÇÃO CONSTITUCIONAL BRASILEIRA

Carlos Bastide Horbach

THE PHILOSOPHY OF INTERNATIONAL LAW IN CONTEMPORARY SCHOLARSHIP: OVERCOMING NE-

GLIGENCE THROUGH THE GLOBAL EXPANSION OF HUMAN RIGHTS

Fabrício Bertini Pasquot Polido, Lucas Costa dos Anjos e Vinícius Machado Calixto

OpORTUNIDADES E DESAFIOS DAS TWAIL NO CONTEXTO LATINO-AMERICANO A PARTIR DE PERSPECTIVAS DOS POVOS INDÍGENAS AO DIREITO INTERNACIONAL

Fernanda Cristina de Oliveira Franco

Por Que uma ANÁlise ECONÔMICA Do DIREITO INTERNACIONAL PÚBLICO? DESAFIOS E PERSPECTIVAS DO MÉTODO NO BRASII

Gustavo Ferreira Ribeiro e Jose Guilherme Moreno Caiado

ANÁliSE ECONÔMICA do DIREITO INTERNACIONAL .263 Michele Alessandra Hastreiter e Luís Alexandre Carta Winter

RACIONALIDADE ECONÔMICA E OS ACORDOS BILATERAIS DE INVESTIMENTO 284 Michele Alessandra Hastreiter e Luís Alexandre Carta Winter

LOOKING FOR A BRICS PERSPECTIVE ON INTERNATIONAL LAW .304 Gabriel Webber Ziero

A INFLUÊNCIA DO DIREITO DESPORTIVO TRANSNACIONAL NO ORDENAMENTO JURÍDICO BRASILEIRO: DA REPRODUÇÃO DE NORMAS À APLICAÇÃO DIRETA PELA JURISDIÇÃO ESTATAL.......................3324 Tiago Silveira de Faria

CONVENCIONALIZAÇÃo DO DIREITO CIVIL: A APLICAÇÃo DOS TRATADOS E CONVENÇÕES INTERNACIONAIS NO ÂMBITO DAS RELAÇÕES PRIVADAS . 
NATIONAL JUdGES AND COURTS AS INSTITUTIONS FOR GLOBAL ECONOMIC GOVERNANCE 356

Juízes e tribunais nacionais como instituições para a governança global 356 Camilla Capucio

Is Trade Governance Changing? 371 Alberto do Amaral Júnior

OS FUNDOS ABUTRES: MEROS PARTICIPANTES DO CENÁRIO INTERNACIONAL OU SUJEITOS PERANTE O DIREITO INTERNACIONAL? 384

Guilherme Berger Schmitt

SHAREHOLDER AGREEMENTS IN PUBLICLY TRADED COMPANIES: A COMPARISON BETWEEN THE

U.S. AND BRAZIL. 402 Helena Masullo

REgulaÇÃo DO INVESTIMENTO ESTRANGEIRO DIRETO NO BRASIL: DA RESISTÊNCIA AOS TRATADOS BILATERAIS DE INVESTIMENTO À EMERGÊNCIA DE UM NOVO MODELO REGULATÓRIO 421 Fabio Morosini e Ely Caetano Xavier Júnior

DA QUALIFICAÇÃo JURÍDiCA dAS Distintas FORMAS DE PRESTAÇão TECNOLÓGICA: BREVE ANÁLISE DO MARCO REGULATÓRIO INTERNACIONAL

Daniel Amin Ferraz

REDEFINING TERRORISM: THE DANGER OF MISUNDERSTANDING THE MODERN WORLD'S GRAVEST THREAT

Jennifer Breedon

As EXECUÇões SELETIVAS E A RESPONSABILIZAÇÃo DE AGENTES TERRORISTAS 485 Alexandre Guerreiro

INTERNATIONAL CRIMINALS AND THEIR VIRTUAL CURRENCIES: THE NEED FOR AN INTERNATIONAL EFFORT IN REGULATING VIRTUAL CURRENCIES AND COMBATING CYBER CRIME Joy Marie Virga

Criminalidad transnacional organizada en el Ámbito del MERCOSUR: ¿Hacia un Derecho Penal Regional?. .528 Nicolás Santiago Cordini e Mariano Javier Hoet 
RUMO À INTERNACIONALIZAÇÃo DA PROTEÇÃO PENAL DO MEIO AMBIENTE: DOS ECOCRIMES AO ECOCÍDIO

Kathia Martin-Chenut, Laurent Neyret e Camila Perruso

Engaging the U.N. Guiding Principles on Business and Human Rights: the inter-AMERICAN COMMISSION ON HUMAN RIGHTS \& THE EXTRACTIVE SECTOR 571 Cindy S. Woods

O DIREITO HUMANO À COMUNICAÇÃo PRÉVIA E PORMENORIZADA DAS ACUSAÇÕES NOS PROCESSOS administrativos: O desprezo do Superior Tribunal de Justiça ao Pacto de San José da Costa Rica e À Corte Interamericana de Direitos Humanos .590

Daniel Wunder Hachem e Eloi Pethechust

A responsabilidade internacional do Brasil em FaCe do CONTRole de ConVENCionaliDADE EM SEDE DE DIREITOS HUMANOS: CONFLITO DE INTERPRETAÇÃO ENTRE A JURISDIÇÃO DA Corte Interamericana de Direitos Humanos e o Supremo Tribunal Federal quanto a LEI DE ANISTIA 612

Carla Ribeiro Volpini Silva e Bruno Wanderley Junior

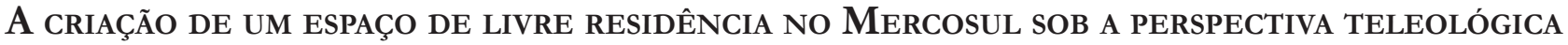
DA INTEGRAÇÃo REGIONAL: ASPECTOS NORMATIVOS E SOCIAIS DOS ACORDOS DE RESIDÊNCIA ....... 631

Aline Beltrame de Moura

A funcionalização como tendênCia evolutiva do Direito Internacional e sua conTRIBUIÇÃO AO REGIME LEGAL DO BANCO DE DADOS DE IDENTIFICAÇÃO DE PERFIL GENÉTICO NO BRASIL

Antonio Henrique Graciano Suxberger

O DIREITO INTERNACIONAL E A PROTEÇÃO DOS DIREITOS DE CRIANÇAS E DE ADOLESCENTES EM CONFLITO COM A LEI EM MOÇAMBIQUE

Bernardo Fernando Sicoche

ObTenÇão de PRovas no EXTERIOR: PARA ALÉM dA LEX FORI E LEX DiLigENTIAE. .685 André De Carvalho Ramos 
A Slight Revenge and a Growing Hope for Mauritius and the Chagossians: The UNClos Arbitral Tribunal's Award of 18 March 2015 on Chagos Marine Protected Area (Mauritius v. United Kingdom)

Géraldine Giraudeau

ANÁLISE DA RESPONSABILIDADE INTERNACIONAL DA UCRÂNIA POR VIOLAÇÃo DOS DIREITOS HUmanos na QUeda do voo da Malaysia Airlines (MH17). .728

Daniela Copetti Cravo

NatureZa JURÍdica do DESENVOLVIMENTO SUSTENTÁVEL No DIREITO INTERNACIONAL ........739 Pedro Ivo Diniz

A INFLUÊNCIA Da SOFT LAW NA FORMaÇão do DiREITo AMBIENTAL .767 Leonardo da Rocha de Souza e Margareth Anne Leister

As COMPLICADAS INTER-RELAÇÕES ENTRE OS SISTEMAS INTERNOS E INTERNACIONAIS DE PROTEÇãO DO DIREITO AO MEIO AMBIENTE SADIO. 785 José Adércio Leite Sampaio e Beatriz Souza Costa 


\title{
Os fundos abutres: meros participantes do cenário internacional ou sujeitos perante o direito internacional?*
}

\author{
Vulture funds: actors in the international \\ system or subjects of international law?
}

Guilherme Berger Schmitt**

\section{Resumo}

O objetivo deste artigo é analisar a atuação dos chamados fundos "abutres" no cenário internacional, nomeadamente no âmbito das dívidas soberanas, perquirindo, com isso, a caracterização jurídica desses fundos perante o direito internacional público. Para tanto, primeiro apresentamos uma definição desses atores específicos, caracterizando-os a partir da sua atuação na seara internacional. Em seguida, analisamos a evolução dos institutos econômicos e jurídicos que hoje permitem o modo de operação dos fundos abutres, alinhavando breves explicações acerca da imunidade jurisdicional dos Estados e da titularização dos créditos das dívidas soberanas. Após a sua caracterização e a explicação do seu contexto de atuação, passamos à análise do papel exercido por esses fundos no âmbito internacional, demonstrando o seu papel de reguladores do mercado das dos créditos das dívidas soberanas. Finalmente, discutimos a possibilidade da atribuição da personalidade jurídica desses atores perante o direito internacional público. Concluímos que o ingresso desses fundos, no âmbito das dívidas soberanas, resultou, diretamente dos "incentivos" jurídico-econômicos presentes na época do seu ingresso no cenário internacional, permitindo o seu modo de operação atualmente empregado. Também é possível concluir que os fundos "abutres" podem ter, com algumas ressalvas, um papel positivo no âmbito das dívidas soberanas e, consequentemente, a possibilidade de ter a si atribuída a característica de direitos de sujeito internacional, embasando as novas teorias da quebra de paradigmas do direito internacional público atual.

Palavras-chave: Fundos abutres. Dívida soberana. Reestruturação da dívida soberana. Imunidade jurisdicional do estado. Sujeitos de direito internacional.

* Recebido em 31/10/2015

Aprovado em 24/11/2015

** Advogando Miliitante. Mestre em Ciências Jurídico-Políticas pela Faculdade de Direito da Universidade de Coimbra. E-mail: gbschmitt@ outlook.com.

\section{Abstract}

The purpose of this article is to analyze the role of vulture funds in the modern international relations, particularly in the context of sovereign debts, thus investigating the nature of these funds towards the international law. To do so, we defined these specific actors, characterizing them through the investigation of their actions in the international system. After that, we analyzed the evolution of the economic and legal institutions that now 
allowed the modus operandi of the vulture funds, throughout brief explanations of the jurisdictional immunity of States and the sovereign debt credits securitization. After their characterization and operational contextualization, we move to the analysis of the international role presented by these funds, demonstrating its role as regulators of the market in the credits of sovereign debt. Finally, we discussed the possibility of granting to these funds legal personality as subjects of international law. We conclude that the international emergence of these funds occurred as a direct result of the legal-economic "incentives" established at the time of their admission into the international system. We also concluded that the vulture funds could have, with some exceptions, a positive role in the context of sovereign debts, and, consequently, a legal personality as subjects of international law. This could indicate that the intricate role of the vulture funds in the international scenario surpass the restricted scope of the sovereign debts, proving the new theories of international law.

Keywords: Vulture funds. Sovereign debt. Sovereign debt restructuring. State immunity. Subjects of international law.

\section{INTRODUÇÃo}

A fim de comprar máquinas agrárias, em 1979, a República da Zâmbia requisitou um empréstimo interestatal de 15 milhões de dólares junto à Romênia. ${ }^{1}$ Não obstante a natureza daquela relação, é possível afirmar que o governo da Zâmbia anteviu que o empréstimo tomado resultaria em uma dívida superior ao valor acordado inicialmente, isto é, previu que o débito poderia aumentar devido à aplicabilidade de quaisquer juros contratuais previstos. Parece improvável, porém, que o governo zambiano pudesse imaginar, na época, que aquela dívida interestatal embasaria, quase trinta anos depois, a reivindicação judicial de um débito superior a 55 milhões de dólares.

O governo da Zâmbia, tampouco, poderia antever, sem dúvida, que aquela pretensão judicial partiria de um fundo privado com sede nas Ilhas Virgens Britânicas e, muito menos, que a pretensão concretizar-se-ia,

1 Cfr. GOREN, Jonathan. State-to-State debts: sovereign immunity and the "vulture" hunt. The George Washington International Law Review, Washington, v. 41, n. 3, p. 681-708, 2010. p. 681. em parte, sob a jurisdição de um Estado estrangeiro. ${ }^{2}$ Certamente, em situações similares, ficaram igualmente atônitos os governantes de diversos outros Estados soberanos que sofreram com estas inesperadas investidas. ${ }^{3}$

Isso porque - como soberanos e protagonistas do direito das gentes ${ }^{4}$ - os Estados sempre gozaram de amplos privilégios e imunidades perante outros membros da comunidade internacional. É difícil imaginar, pois, que os governantes estatais e até mesmo os autores jusinternacionalistas clássicos pudessem, algum dia, admitir um cenário no qual uma entidade privada tivesse poderes não só para os "enfrentar" judicialmente, mas, também, para manter - abertamente e por meio da ordem legal de uma jurisdição estrangeira — um Estado soberano sob as suas "garras". Hoje, porém, a situação é diferente.

A diluição das fronteiras estatais, claramente acelerada pela globalização, acabou por revelar a interdependência estabelecida entre os diversos atores internacionais ${ }^{5}$, tornando imprudente negar a forte influência que

2 Conquanto o direito de cobrança dos autores tenha sido reconhecido, o processo judicial não teve o desfecho por eles esperado, pois embora tenham requerido 55 milhões de dólares, a Corte responsável pelo caso acabou por conceder aos autores, em audiência realizada em abril de 2007, "somente" 15,5 milhões de dólares, que ainda representaram um excelente lucro quando comparado aos 3,2 milhões pagos pelo direito de cobrança da dívida. Veja-se, a respeito, AREWA, Olufunmilayo B. Vultures, hyenas, and african debt: private equity and Zambia. Northwestern Journal of International Law and Business, Chicago, v. 29, n. 3, p. 643-674, July/Sept. 2009. p. 646. 3 A lista de Estados que sofreram com investidas judiciais de fundos privados é grande. Podemos listar, não exaustivamente, países como: Argentina, Brasil, Peru, Zâmbia, Equador, Congo, Libéria e diversos outros. Cfr. SCHUMACHER, Julian; TREBESCH, Christoph; ENDERLEIN, Henrik. Sovereign defaults in court: the rise of creditor litigation 1976-2010. Social Science Research Network, June 2013. p. 37-38. Available at: <http://www.scu.edu/business/economics/upload/SovereignDefaultsinCourt.pdf $>$. Accessed on: 16 dec. 2015.

4 Embora dividam os holofotes com outros sujeitos de emergente importância, se não maior, pois muito se fala a respeito da superação do modelo estatal de Vestefália e do crescente reconhecimento dos indivíduos como sujeitos primários de direito internacional, os Estados ainda podem ser considerados - como grande parte da doutrina assim o faz - como a espinha dorsal da comunidade internacional. Vejam-se, sobre o assunto, inter alia, MACHADO, Jónatas Eduardo Mendes. Direito internacional: do paradigma clássico ao pós-11 de setembro. 2. ed. Coimbra: Coimbra, 2004. p. 213-215; ALMEIDA, Francisco Ferreira de. Direito internacional público. 2. ed. Coimbra: Coimbra, 2003. p. 200-201; CASSESE, Antonio. International law in a divided world. Oxford: Clarendon Press, 1986. p. 74-77; SHAW, Malcolm N. International law. 6. ed. Cambridge: Cambridge University Press, 2008. p. 197 e ss; BRITO, Wladmir. Direito internacional público. Coimbra: Coimbra, 2008. p. 333-334.

5 Cfr., a propósito, MACHADO, Jónatas Eduardo Mendes. Direito 
os entes privados exercem hoje no cenário internacional, inclusive sobre os Estados soberanos. ${ }^{6}$ Não é de se estranhar, portanto, que as ações internacionais destes fundos vêm sendo acompanhadas de perto pela mídia, pela comunidade acadêmica jusinternacionalista e por Organizações e personalidades internacionais. O caso que entrelaçou a República da Argentina e o fundo de investimento MNL Capital, por exemplo, que ainda está se desenrolando em tribunais nacionais e internacionais, vem atraindo muita atenção, sendo rotulado, inclusive, como o "julgamento do século".

Note-se que, muito embora a sua presença não tenha sido bem-vinda pela sociedade internacional como um todo, e que não haja dúvida acerca da nebulosidade ético-moral das suas ações, parece certo que esses novos atores já possuem um papel definido no cenário internacional, com grande parte da sua prática fundamentada em normas legais, sejam internas ou internacionais. Por outro lado, a caracterização desses fundos abutres como sujeitos perante o Direito Internacional ainda parece padecer de exatidão. É, portanto, nessa conjectura que este estudo pretende analisar o papel e a atuação desses fundos na sociedade internacional, auxiliando na caracterização da natureza desses novos atores perante o Direito Internacional.

\section{Os FUNDOS "ABUtRES"}

Não é novidade o fato de que, recentemente, a mídia internacional passou a destacar com maior intensidade a ação dos chamados fundos "abutres" no cenário internacional. ${ }^{7}$ Atualmente, não é raro, portanto, deparar-se

internacional: do paradigma clássico ao pós-11 de setembro. 2. ed. Coimbra: Coimbra, 2004. p. 465-466.

6 A influência econômica destes atores pode ser percebida com clareza, por exemplo, no contexto da atuação dos fundos "abutres" nas dívidas soberanas, nomeadamente nos casos que envolvam países fragilizados e altamente endividados, uma vez que estes países não apresentam, em geral, resistência às investidas destes fundos. Cfr., sobre este ponto, PROCTOR, Charles. Vulture funds and sovereign debt: the Zambian experience. Journal of South African Law, Philadelphia, n. 4, p. 629-641, 2007. p. 629. Acerca da influência dos atores privados no cenário internacional e, inclusive, sobre o Direito Internacional, veja-se, inter alia, GARCIA, Frank J. Globalization, power, states, and the role of law. Boston College Law Review, Boston, v. 54, n. 3, 903-919, 2013. p. 908.

7 Em meados de 2005, as ações dos fundos “abutres" já permeavam as notícias internacionais, porém, em 2007, com a conclusão do caso que envolveu o fundo de investimento Donegal e a República da Zâmbia, o assunto passou a frequentar as manchetes internacio- com diversas reportagens, publicadas nos mais variados jornais de renome internacional, que utilizam esta alcunha pejorativa como chamariz à atuação global destes novos atores. O termo é utilizado e repetido, por meio da sua tradução literal, em diferentes línguas, mantendo o núcleo e o "valor" inicialmente atribuídos à expressão. ${ }^{8}$

As reportagens apresentadas - muitas vezes parciais e com agendas secundárias ${ }^{9}$ - , todavia, normalmente relacionam a ação destes fundos somente a aspectos políticos, não apresentando, assim, análises jurídicas ou econômicas da sua ação no cenário internacional. A classificação mais aprofundada desses fundos - que envolve aspectos jurídicos, econômicos, sociais e, por vezes, morais - parece ter ficado a cargo da comunidade acadêmica. Isso porque, diversos autores já contribuíram à identificação destes novos atores econômicos, bem como à análise dos reflexos que as ações destes fundos geram no âmbito jurídico, nomeadamente no cenário internacional.

Note-se, assim, que, embora largamente utilizado,

nais com maior intensidade Segundo uma reportagem do Financial Times, se pesquisássemos no mecanismo de busca Google as palavras "Sheehan" e "vulture funds", encontraríamos, em 2007, mais de 62 mil resultados referentes à pesquisa. Nesse sentido, cfr. HURLEY, Gail. Taming the vultures: are new measures enough to protect debt relief gains? Belgiui: Eurodad, dez. 2008. p. 4. Available at: < http:// eurodad.org/uploadedfiles/whats_new/reports/the $\% 20$ rise $\% 20$ of $\% 20$ the $\% 20$ vulture $\% 20$ layout.pdf $>$. Accessed on: 16 dec. 2015. Desde o final de 2011, porém, com o desenrolar das decisões proferidas nos casos que se desenvolveram a partir da moratória argentina de 2001, as mídias internacionais foram "dominadas" pela grande onda de atenção que as ações destes fundos vêm atraindo. $\mathrm{O}$ efeito do caso do "século" não se limita, porém, somente às notícias referentes ao específico caso da Argentina. Hoje, no início de 2014, ao realizar a mesma pesquisa feita pelo Financial Times em 2007, ou seja, no mesmo mecanismo de busca e com as mesmas palavras, deparamo-nos com mais de 2 milhões de resultados acerca dos fundos "abutres".

8 Vejam-se, por exemplo, os termos fonds vautours, fondos buitres e geierfonds, que são utilizados, respectivamente, pela mídia francesa, espanhola e alemã.

9 Com inúmeros interesses secundários em jogo, assim como diversos outros tópicos que são objetos centrais dos debates que fazem parte do cenário internacional, o assunto que envolve os fundos "abutres" não pode ser pinçado dos jogos políticos internos e internacionais. Não é de se estranhar, destarte, que diversas reportagens acerca dos fundos "abutres", que se encontram vinculadas nas mídias internacionais, inclusive em jornais de destaque, estão repletas de informações e opiniões parciais. É o caso, geralmente, dos artigos publicados nos meios de informação ligados aos Estados que sofreram diretamente com a ação destes fundos. É o que ocorre, igualmente, nas notícias que são de autoria de indivíduos diretamente vinculados às partes envolvidas nas querelas dos fundos abutres. 
o termo "fundo abutre" não reflete, ainda, uma classificação oficial, tampouco incontestável. É possível afirmar, contudo, que os fundos de investimento que recebem esse rótulo apresentam algumas características em comum. Assim, caso fosse necessário apresentá-los de maneira breve e simplista, poderíamos afirmar que os fundos "abutres" nada mais são do que credores secundários, normalmente organizados sobre a forma de fundos de hedge, que obtêm seu lucro por meio da especulação e da cobrança de títulos de dívidas soberanas. ${ }^{10}$ Seria possível afirmar, ademais, que a busca lucrativa desses fundos se dá, geralmente, pela via judicial. ${ }^{11}$

É importante salientar, destarte, que essa nomenclatura nada mais é do que um rótulo utilizado para identificar, de maneira negativa, credores que empregam, comumente, um determinado modus operandi no âmbito internacional. Alguns autores refutam, portanto, a utilização dessa expressão, referindo-se aos investidores como distressed debt investors.12 Outros, inclusive, não

10 Cfr., a propósito AREWA, Olufunmilayo B. Vultures, hyenas, and african debt: private equity and Zambia. Northwestern Journal of International Law and Business, Chicago, v. 29, n. 3, p. 643-674, July/ Sept. 2009. p. 647; SILVA, Alexandre Pereira da; PEREIRA, Mariana Yante Barrêto. "Fundos abutres" vs. Estados nacionais: soberania e atuação do Tribunal Internacional do Direito do Mar a partir do caso da fragata libertad. Revista de Direito Internacional, Brasília, v. 10, n. 1, 2013. p. 138.

11 Sobre este ponto, vejam-se, inter alia, NGUYEN, Davy V.H. Too Big to Fail? Towards a Sovereign Bankruptcy Regime. Cornell International Law Journal, New York, v. 45, n. 3, p. 697-723, 2012. p. 699; AVERY, Ryan E. Out of the desert and to the Oasis: legislation on predatory debt investing. University of Miami International and Comparative Law Review, Miami, v. 18, n. 2, p. 267-290, 2011. p. 276; BROOMFIELD, Elizabeth. Subduing the vultures: assessing government caps on recovery in sovereign debt litigation. Columbia Business Law Review, washington, v. 2010, n. 2, p. 473-528, 2010. p. 475; MONTELEONE, Theresa A. A vulture's gamble: high-stakes interpretation of sovereign debt contracts in NML Capital, Ltd v Republic of Argentina. Capital Markets Law Journal, Oxford, v. 8, n. 2, p. 149-165, 2013. p. 154.

12 Vejam-se, a título exemplificativo, GOREN, Jonathan. Stateto-State debts: sovereign immunity and the "vulture" hunt. The George Washington International Law Review, Washington, v. 41, n. 3, p. 681-708, 2010. p. 681; SOOKUN, Devi. Stop vulture fund lawsuits: a handbook. London: Commonwealth Secretariat, 2010. p. 7. A utilização de termos imparciais também se faz presente em documentos estatais oficiais. Em português, por exemplo, podemos encontrar o emprego da expressão "Fundo de Situação Especial" para referir aos chamados "fundos abutres". Cfr., neste sentido, BRASIL. Ministério das Relações Exteriores. Comunicado Conjunto dos Presidentes dos Estados Partes do Mercosul. \24. Disponível em: <http://www.itamaraty.gov.br/index.php?option $=$ com_content $\&$ view $=$ article\&id $=3$ 250:comunicado-conjunto-dos-presidentes-dos-estados-partes-domercosul-brasilia-7-de-dezembro-de-2012\&catid $=42 \&$ lang $=$ pt-BR\&Itemid=280>. Acesso em: 15 dez. 2015. utilizam rótulo algum, remetendo-se aos fundos apenas pela sua classificação maior, isto é, referindo-se aos investidores como fundos de hedge que atuam no mercado internacional.

Dessa forma, devido à falta de padronização em sua nomenclatura, o entendimento das particularidades destes fundos se faz de suma importância, uma vez que a compreensão aprofundada das características destes novos atores econômicos pode prevalecer sobre qualquer termo a eles aplicado, permitindo ao leitor, assim, identificar um núcleo comum em diferentes rótulos.

Para tanto, parece fundamental entender, primeiramente, a natureza desses atores como fundos de investimento per se, ou seja, entender o seu funcionamento como um fundo de hedge. ${ }^{13}$ Isso porque, parece correto afirmar que grande parte do modo de operação empregado pela "espécie" dos "abutres" deriva diretamente das características intrínsecas ao modelo de operação aplicado pelos fundos de hedge.

Nesse sentido, de maneira extremamente breve, é possível afirmar que os fundos de hedge são particularmente conhecidos por proporcionar um alto retorno ${ }^{14}$ de investimento a um restrito ${ }^{15}$ grupo de investidores. Ressalte-se, que a presença desses característicos fundos de investimento não é inédita, tampouco recente, no âmbito privado, pois esses fundos especializaram-se, numa das vertentes do seu modo de operação, na compra de débitos de empresas que se encontram em dificuldades, uma vez que a emergência na venda dos títulos desses empreendimentos, em situações críticas, pode gerar descontos atraentes sobre o preço dos seus títulos de crédito. Mediante o início do processo de falência ou, em alguns casos, inclusive, perante a simples ameaça de falência dessas empresas, os credores primários podem reagir negativamente à possível desvalorização das ações questão em sua posse, optando, assim,

13 Cfr. NGUYEN, Davy V. H. Too big to fail? Towards a sovereign bankruptcy regime. Cornell International Law Journal, New York, v. 45, n. 3, p. 697-723, 2012. p. 699; SILVA, Alexandre Pereira da; PEREIRA, Mariana Yante Barrêto. "Fundos abutres" vs. Estados nacionais: soberania e atuação do Tribunal Internacional do Direito do Mar a partir do caso da fragata libertad. Revista de Direito Internacional, Brasília, v. 10, n. 1, 2013. p. 138.

14 Veja-se LO, Andrew W. Risk management for hedge funds: introduction and overview. Financial Analysts Journal, Stanford, v. 57, n. 6, p. 16-33, Nov./Dec. 2001. p. 16-17.

15 Cfr. FUNG, William; HSIEH, David A. Empirical characteristics of dynamic trading strategies: the case of hedge funds. Review of Financial Studies, Oxford, v. 10, n. 2, p. 75-302, 1997. p. 281. 
pela venda dos créditos e não pela continuação do seu investimento prévio. ${ }^{16}$

A situação criada pelo stress dessas empresas é vista pelos fundos de hedge, diferentemente do que ocorre com outros fundos tradicionais, como uma oportunidade de investimento. Isto porque, quando realizada abaixo do preço integral, a compra de títulos de créditos empresariais pode gerar uma alta taxa de lucratividade em curtos períodos de tempo. A aposta na recuperação ou, inclusive, na renovação dessas empresas, que pode se dar, respectivamente, antes ou após o processo de falência, pode gerar altos retornos aos investidores que souberem gerir, corretamente, as suas aplicações.

Note-se, porém, que essa específica via de aplicação só tem possibilidade de maximizar o retorno dos seus investidores se a compra dos créditos for efetuada quando estes se encontram em baixa, isto é, em situações críticas. Portanto, o primeiro grande traço característico desses fundos (ao menos quando nos referimos ao mercado empresarial e das dívidas soberanas), refere-se à posição que eles ocupam, relativamente, aos credores e ao mercado de débitos. Os fundos de investimento não são credores primários ou originários, pelo contrário, eles adquirem seus débitos por meio dos mercados secundários, quando os títulos se encontram à venda por preços abaixo do seu valor nominal.

A agressiva e oportunista estratégia desses fundos pode facilitar, de certo modo, uma oposição ética às suas ações, uma vez que esses fundos lucram enquanto outros investidores, nomeadamente os primários, são obrigados a realizar sacrifícios financeiros e materiais. ${ }^{17}$ Porém, embora alguma resistência inicial possa existir, a sua atuação encontra grande aceitação e defesa interna, uma vez que esses fundos têm importante papel na manutenção dos mercados econômicos internos. ${ }^{18}$

16 Cfr LHABITANT, François-Serge. Handbook of hedge funds. England: J. W. and Sons, 2011. p. 226-227.

17 Veja-se LHABITANT, François-Serge. Handbook of hedge funds. England: J. W. and Sons, 2011. p. 215.

18 A participação dos fundos de bedge no processo de falência empresarial pode ser interessante para todos envolvidos, pois, segundo alguns autores, a presença dos fundos de bedge nesses processos pode auxiliar na manutenção do equilíbrio dos poderes entre as partes presentes no processo da falência e, por vezes, inclusive, na própria recuperação das empresas devedoras. O equilíbrio entre as partes envolvidas no processo é benéfico especialmente para aqueles pequenos fundos ou acionistas privados que não possuem um poder aquisitivo equiparável às grandes empresas. Isto porque, os fundos de hedge, além de possuir grande poder aquisitivo, possuem experiência nestes processos, o que acaba por equilibrar o poder entre a parte
Grande parte das discussões referentes à presença dos fundos "abutres" nos âmbitos privados encontra-se, porém, afastada ou desligada de fatores sociais ou éticos, circunscrevendo-se, assim, a fatores puramente econométricos. ${ }^{19}$ Entrementes, a presença e a atuação desses fundos no mercado internacional incitam debates mais profundos que envolvem, além das questões econômicas, aspectos morais, jurídicos e, mais importante, humanos. Isso porque, diferentemente do que ocorre no âmbito privado (no qual a integridade dos credores e dos devedores é protegida internamente pelas leis de falência), as ações dos fundos "abutres" no mercado das dívidas soberanas ainda não se encontram diretamente limitadas ou reguladas, sejam por normas internas ou internacionais. Inexistem, por exemplo, normas ou institutos que garantam, nessa específica situação, a proteção dos Estados altamente endividados, tampouco existem normas que garantam proteção aos cidadãos desdesses Estados que se encontrem em situação crítica.

Assim, embora compartilhem das características gerais dos fundos de investimento de hedge, os fundos que atuam no mercado internacional apresentam algumas especificidades próprias, que em muito advêm do seu particular âmbito de atuação, destacando-os dos restantes fundos de investimento e, inclusive, de outras variações de fundos hedge. A presença e atuação desses fundos no âmbito internacional, por exemplo, diferentemente do que ocorre nos mercados internos, não pa-

devedora e os pequenos acionistas. Ver, nesse sentido, WEI, Jiang; KAI, Li; WEI, Wang. Hedge funds and chapter 11. The Journal of Finance, v. 67, n. 2, p. 513-559, 2012. p. 513; 555; 556. As empresas, por seu lado, podem ser beneficiadas com a participação dos fundos de hedge no processo de falência devido à provável lucratividade que os fundos podem atingir caso as empresas se recuperem, seja durante o processo ou, nos piores casos, com uma renovação após a falência. Muitos dos fundos de bedge são geridos por profissionais capacitados, com larga experiência no âmbito empresarial, que, como novos acionistas destas empresas "necessitadas", passam a buscar a sua recuperação a fim de garantir o retorno do seu investimento inicial. Vejam-se, nesse sentido, WOLLASTON, Andrew. The growing importance of debt in European corporate transactions. Insolvency Intelligence, London, v. 18, n. 10, p. 145-149, 2005. p. 147-148; YAP, Suniati. Investing in chapter 11 companies: vultures or white knights?. Southewestern Journal of Law and Trade in the Americas, California, v. 2, p. 153-174, Mar./Apr. 1995. p. 153-155; 174.

19 É importante salientar, porém, que existem exceções que, inclusive, argumentam que os comportamentos destes fundos estão em consonância com o ambiente no qual eles se inserem. Cfr. CARSON, Scott Alan. Vulture investors, predators of the $90 \mathrm{~s}$ : an ethical examination. Journal of Business Ethics, Berlin, v. 17, n. 5, p. 543-555, 1998. p. 555. 
rece encontrar muitos defensores. Não é de se estranhar, portanto, que, conquanto os agressivos fundos de hedge já fossem identificados como "abutres" dos mercados internos, foram exatamente as suas atuações nos mercados internacionais - nomeadamente no mercado das dívidas soberanas - que renderam maior conexão destes fundos com o seu adjetivo pejorativo.

Isso porque, se a busca por lucros em detrimento do desenvolvimento de alguns Estados já não bastasse para prejudicar a reputação desses fundos no cenário internacional, o caminho por eles trilhado soma-se aos argumentos utilizados por aqueles que se opõem às ações desses fundos. Os abutres são aves facilmente reconhecidas pela sua cor e pelo seu característico hábito de caça. Muito paciente, o abutre geralmente sobrevoa sua presa até que ela se apresente indefesa ou morta, para, então, alimentar-se da sua fragilizada presa ou da carcaça deixada por outros animais. Os chamados fundos "abutres" são igualmente conhecidos por averiguar e esperar pacientemente para "atacar" as suas fragilizadas presas, nesse caso, países que se encontrem em situações emergenciais.

O sucesso da caçada desses "predadores" econômicos, porém, igualmente ao ocorrido com as aves de rapina, não depende somente da escolha das suas presas, pois o momento da investida é igualmente importante e deve ser meticulosamente calculado. Não é de se estranhar, pois, que os fundos "abutres" sejam reconhecidamente responsáveis por "atacar" países agraciados pelo programa de incentivo à recuperação dos países altamente endividados (HIPC) $)^{20}$.

20 Em 2010 estimava-se que credores privados haviam conseguido mais de um bilhão de dólares em julgamentos favoráveis face aos países mais pobres do mundo. Em relação a esse grande grupo de credores privados, os fundos "abutres" são responsáveis por $65 \%$ dos processos iniciados perante os chamados HIPC. Segundo os fundos "abutres", seus ataques aos países agraciados por esses programas de recuperação se fundamentam no fato de que os países atacados — antes altamente endividados — passam a ter, após o alívio das dívidas, externas, condições de cumprir com as obrigações financeiras previamente adquiridas. Em 2007, por exemplo, o fundo de investimento Donegal acionou judicialmente o governo da Zâmbia devido a um débito de 42 milhões de dólares. Curiosamente, a quantia requerida era equivalente a todo o alívio da dívida que o governo da Zâmbia havia recebido no ano anterior ao processo. A este respeito, veja-se: ZAMBIA loses 'vulture fund' case. BBC News, London, Feb 15, 2007. Available at: < http://www. scu.edu/business/economics/upload/SovereignDefaultsinCourt. pdf $>$. Accessed on: 16 dec. 2015. Vejam-se SCHUMACHER, Julian; TREBESCH, Christoph; ENDERLEIN, Henrik. Sovereign defaults in court: the rise of creditor litigation 1976-2010. Social Science Research Network, June 2013. Available at: <http://news.bbc.
Além do mais, ao buscar a maximização dos seus lucros, os fundos "abutres" negam-se a participar das reestruturações dos débitos, uma vez que essas negociações envolvem, geralmente, a redução dos débitos.

Esses fundos apresentam-se, assim, como um tipo específico de credor, compreendendo-se no grupo dos chamados hold-out creditors. 21 Isso porque, mediante uma oportunidade de troca dos títulos, durante uma reestruturação de dívida, os fundos "abutres" "seguram" seus títulos a fim de buscar uma oportunidade mais rentável. Essa "oportunidade" mais rentável, conforme já dito, é geralmente atingida pela via judiciária ou, ainda, por meio de negociações alavancadas pela ameaça dos processos. As ações desses chamados hold-out creditors obstruem, destarte, conforme se verá adiante, o bom andamento da reestruturação das dívidas dos Estados devedores. Certamente, o atraso das reestruturações pode prejudicar a economia desses Estados, refletindo, diretamente, no bem-estar dos seus cidadãos.

Não é à toa, portanto, que o termo "fundos abutres", que é claramente utilizado de maneira pejorativa, foi largamente difundido pela comunidade internacional. A alusão ao grande predador no termo utilizado para caracterizar estes fundos é, portanto, geralmente utilizada em referência à sua nefasta maneira de atuar.

\section{O NINHO DOS ABUTRES: AS DÍVIDAS SOBERANAS}

Não há dúvida de que a principal característica dos fundos "abutres" e a principal diferença destes para os demais fundos de hedge, nomeadamente com relação àqueles que atuam internamente, advêm da escolha do seu âmbito, ou mercado, de atuação. Ao contrário do que ocorre com a generalidade dos fundos de hedge, os fundos "abutres" buscam o retorno do investimento dos seus integrantes por meio da especulação do mer-

co.uk/2/hi/business/6365433.stm>. Accessed on: 16 dec. 2015. p. 3; BROOMFIELD, Elizabeth. Subduing the vultures: assessing government caps on recovery in sovereign debt litigation. Columbia Business Law Review, Washington, v. 2010, n. 2, p. 473-528, 2010. p. 475. Veja-se, para uma lista dos países que se "qualificaram para, são elegíveis ou potencialmente elegíveis, e que podem querer receber ajuda da Iniciativa HIPC", IMF. Debt Relief Under the Heavily Indebted Poor Countries (HIPC) Initiative Factsheet. HIPC Initiative (2013).

21 Cfr. WHEELER, Christopher C.; ATTARAN, Amir. Declawing the vulture funds: rehabilitation of a comity defense in sovereign debt litigation. Stanford Journal of International Law, Stanford, v. 39, p. 253-284, 2003. p. 254. 
cado das dívidas soberanas.

Porém, embora o mercado das dívidas soberanas apresente contexto muito mais complexo do que aquele presente nos mercados internos, o modus operandi empregado pelos "abutres" não se distancia, em muito, daquele utilizado internamente, uma vez que ambos se caracterizam como credores secundários. Isso, porque, no cenário internacional, os títulos de débito soberanos são adquiridos pelos fundos "abutres" em um mercado paralelo, geralmente por um valor inferior ao preço nominal dos débitos. ${ }^{22}$

Encontrando seus primórdios no período posterior à Segunda Guerra Mundial, o mercado das dívidas soberanas se estabeleceu a partir dos acordos de Bretton Woods, que, inicialmente, foram elaborados, a fim de assegurar a estabilidade econômica internacional no caótico cenário econômico internacional de período caótico 1945, garantindo aos Estados a possibilidade de alavancar a sua economia interna por meio de arrecadações externas de empréstimos oficiais e supranacionais. Em meados da década de 70 , porém, o cenário internacional presenciou uma radical mudança nos padrões econômicos internacionais. Os empréstimos, que antes eram assegurados pelo FMI, passaram a ser concedidos por bancos comerciais norte-americanos e europeus. ${ }^{23}$

Com a crise latino-americana de 1980 e, consequentemente, com as diversas moratórias dos países endividados, os bancos credores passaram a renegociar e remanejar as dívidas soberanas em um mercado secundário. ${ }^{24}$ Ressalte-se que, diferentemente do que ocorre

22 No caso que envolveu a República da Zâmbia, por exemplo, a dívida inicial adquirida em 1979 era de 15 milhões de dólares americanos. Os títulos da dívida soberana, porém, foram comprados, em 1999, por um fundo privado identificado como um fundo "abutre", por 3,2 milhões de dólares (enquanto a dívida corrigida atingia, aproximadamente, a quantia de 30 milhões de dólares). Entrementes, o fundo de investimento cobrou judicialmente, em 2007, uma quantia de mais de 55 milhões de dólares. Se considerarmos que o valor total do débito atingia, em 1999, 44 milhões de dólares (números identificados no litígio, compostos pela correção do valor total mais os juros), é possível afirmar que o pagamento realizado fundo de investimento não chegou a $7,5 \%$ do valor real da dívida. O julgamento final acabou por conceder 15 milhões de dólares ao fundo Donegal. A quantia concedida, mesmo longe dos 55 milhões pretendidos, representou uma margem de lucro de mais de $480 \%$ sobre o valor do investimento inicial.

23 Cfr. HAYS II, James M. "The Sovereign Debt Dilemma. Brooklyn Law Review, New York, v. 75, n. 3, p. 905-933, 2010. p. 913.

24 O governo norte-americano adotou, por meio da sua Reserva Federal, uma política de aumento das taxas de juros nominais. Essa nova política conseguiu combater as taxas de inflação, reduzindo- hoje, na época, apesar das diversas declarações de moratórias dos devedores e das diversas reestruturações das dívidas soberanas, pouquíssimas ações judiciais alimentaram-se dos conflitos. Isso porque, inicialmente, as dívidas eram apenas negociadas entre os próprios bancos e, ademais, os Estados gozavam de imunidades jurisdicionais que ainda encontram algum (muito embora pouco) respaldo em doutrinas absolutistas. ${ }^{25}$

A titularização dos créditos das dívidas soberanas, estabelecida pelo "Plano Brady"26, contudo, transfor-

as substancialmente. A nova política, somada à redução da inflação norte-americana, resultou em um aumento acentuado nas taxas de juros reais previstos nos acordos de débito. $\mathrm{O}$ aumento nas taxas de juros norte-americanas atingiu especialmente os Estados devedores latino-americanos, pois a maioria dos empréstimos concedidos a estes países tinha uma taxa de juros flutuante, ou seja, a taxa de juro cobrada seguia a variação do mercado. Cfr. HAYS II, James M. "The Sovereign Debt Dilemma. Brooklyn Law Review, New York, v. 75, n. 3, p. 905-933, 2010. p. 913; EDWARDS, Sebastian. Crisis and reform in Latin America: from despair to hope. New York: Oxford University, 1995. p. 22; GOLDMAN, Samuel E. Mavericks in the market: the emerging problem of hold-outs in sovereign debt restructuring. UCL A Journal of International Law and Foreign Affairs, California v. 5, p. 159-197, 2000. p. 61; POWER, Philip J. Sovereign debt: the rise of the secondary market and its implications for future restructurings. Fordham Law Review, New York, v. 64, n. 6, p. 2071-2077, Sept./ Mar. 1996.

25 O movimento de aplicação das imunidades jurisdicionais do Estado teve, inicialmente, uma fase que é, geralmente, expressada pela doutrina como "absoluta". Alguns autores relutam, porém, em utilizar o adjetivo, ao menos sem apontar as suas particularidades. Isto porque, segundo estes autores, as imunidades jurisdicionais do Estado não foram, nem durante a sua primeira fase de aplicação, "absolutas". MADRUGA observa, por exemplo, que nos casos de ações relativas a imóveis nunca se estranhou a submissão do Estado estrangeiro ao forum rei sitae. SHAW igualmente afirma que há alguma limitação à teoria absoluta das imunidades jurisdicionais do Estado. Segundo o autor " [t] here is some limitation to the absolute immunity rule to the extent that a mere claim by a foreign sovereign to have an interest in the contested property would have to be substantiated before the English court would grant immunity. Since this involves some submission by the foreign sovereign to the local jurisdiction, immunity is not unqualifiedly absolute". Alguns autores empregam, pois, termos alternativos para expressar a aplicação absoluta das imunidades jurisdicionais do Estado. Termos como "imunidade plena" e "imunidade extensiva" são encontrados na doutrina como alternativas ao termo "imunidade absoluta". Vejam-se, neste sentido, MADRUGA FILHO, Antenor Pereira. $A$ renúncia à imunidade de jurisdição pelo Estado brasileiro e o novo direito da imunidade de jurisdição. São Paulo: Renovar, 2003. p. 178; SHAW, Malcolm N. International law. 6. ed. Cambridge: Cambridge University Press, 2008. p. 703; CARVALHO, Geraldes de. Da imunidade jurisdicional dos Estados estrangeiros. Colectânea de Jurisprudência, Ano 10, Tomo IV, 1985, p. 35-37.

26 De maneira sintética, o plano propunha o agrupamento de todas as dívidas de um determinado devedor, para, então, mediante um desconto no débito total, transformá-las em títulos "Brady" que poderiam ser livremente oferecidos e transacionados pelo público geral. Após a securitização das dívidas, as obrigações originais do 
mou a antiga pequena e, relativamente, homogênea classe de credores em uma classe muito maior e mais diversificada. ${ }^{27}$ Não seria exagero, destarte, afirmar que a expansão do mercado secundário e a facilidade da comercialização dos títulos securitizados são responsáveis por espalhar a titularidade das dívidas soberanas por milhares de credores que variam de enormes instituições a simples investidores privados. Note-se, ademais, que esse processo foi acelerado pelo processo de globalização, uma vez que o fácil acesso a informações mundiais, a interdependência política e, principalmente, econômica, que se estabeleceram no cenário internacional, facilitaram, por um lado, a compra e o acesso dos investidores a novas oportunidades de investimentos; e, por outro lado, dificultaram o reconhecimento e a identificação destes credores. ${ }^{28}$

Porém, não seria correto responsabilizar, exclusivamente, aquelas mudanças político-econômicas pela problematização atual das reestruturações soberanas. A evolução nos arquétipos jurídicos, nomeadamente com relação à cobrança das dívidas soberanas, foi essencial à permissibilidade legal do atual modus operandi utilizado pelos fundos "abutres".

Destarte, se os fundos "abutres" estabeleceram o seu "ninho" no cenário internacional após a grande de 1980 e a titularização dos créditos das dívidas soberanas, certamente é possível afirmar que as evoluções jurídicas, nomeadamente dos paradigmas relativos à imunidade jurisdicional do Estado, detêm parcela substancial na proliferação e na possibilidade da permanência destes fundos no seu novo "habitat". Isso porque, seja com base nas normas consuetudinárias, seja com

país devedor, que se encontravam sob a forma de diversos contratos, eram extintas. Cfr. FISCH, Jill; GENTILE, Caroline. Vultures or vanguards?: the role of litigation in sovereign debt restructuring. Emory Law Journal, Atlanta, v. 53, n. 1043, p. 1047-1116, 2004. p. 1071; POWER, Philip J. Sovereign debt: the rise of the secondary market and its implications for future restructurings. Fordham Law Review, New York, v. 64, n. 6, p. 2071-2077, Sept./ Mar. 1996.

27 Vejam-se, HAYS II, James M. "The Sovereign Debt Dilemma. Brooklyn Law Review, New York, v. 75, n. 3, p. 905-933, 2010, p. 912915; POWER, Philip J. Sovereign debt: the rise of the secondary market and its implications for future restructurings. Fordham Law Review, New York, v. 64, n. 6, p. 2071-2077, Sept./ Mar. 1996. p. 2763.

28 A reestruturação do débito de títulos soberanos argentinos em 2001 envolveu, por exemplo, uma negociação com centenas de milhares de credores que possuíam, ao todo, mais de cento e quarenta tipos de títulos regidos por diversas moedas e leis diferentes. Cfr. WAIBEL, Michael. Sovereign defaults before International courts and tribunals. Cambridge: Cambridge University, 2011. p. 16. base nas normas internas ${ }^{29}$, hoje não há hesitação por grande parte da doutrina em afirmar que as normas de Direito Internacional que versam sobre as imunidades jurisdicionais do Estado devem ser aplicadas à luz da interpretação e aplicação restrita, sendo vistas como uma garantia essencial ao bom funcionamento do mercado econômico internacional, pois a prática evita "distorções de concorrência causadas pelo recurso abusivo à imunidade soberana dos Estados por parte das entidades públicas envolvidas na prática de atos de comércio." 30

Não há dúvidas, portanto, que a doutrina das imunidades jurisdicionais do Estado têm uma íntima relação com a presença dos fundos "abutres" no cenário internacional, bem como com o funcionamento do modo de operação por eles empregado, pois a manutenção da existência desses atores, como entidades econômicas, incita a busca pela alternativa mais lucrativa que estes fundos possam conseguir. A alternativa mais rentável para estes fundos se dá, por certo, por meio da busca do ressarcimento dos seus investimentos pela via judicial, operação esta que seria extremamente ineficiente caso as imunidades jurisdicionais do Estado ainda fossem "absolutas". Note-se que outros institutos como a cortesia internacional, a teoria do ato do Estado e as normas anti-champerty também poderiam representar um duro golpe econômico aos procedimentos dos fundos abutres, mas a história parece apontar em sentido contrário. $^{31}$

29 A nova tendência da aplicação qualificada das imunidades jurisdicionais do Estado foi, assim, ancorada principalmente pelo estabelecimento de leis internas como o Foreign Sovereign Immunities Act (FSIA), proclamado em 1972 nos Estados Unidos da América, e o State Immunity Act, que logo seguiu a legislação norte-americana, sendo proclamado em 1976 no Reino Unido. Não obstante o seu caráter internacional, também se faz importante mencionar aqui as legislações regionais como, por exemplo, a Convenção Europeia sobre a Imunidade dos Estados, de 1972. Para uma visão mais aprofundada sobre estas legislações internas, vejam-se DOLINGER, Jacob. A imunidade jurisdicional dos Estados. Revista de informação legislativa, Brasília, v. 19, n. 76, p. 5-64, 1982. p. 20-36; PELLET, Alain; DINH, Nguyen Quoc; DAILLIER, Patrick. Direito internacional público. Lisboa: Calouste Gulbenkian, 2003. p. 462-463.

30 A aplicação restritiva das imunidades jurisdicionais do Estado sempre encontrou refúgio nas cortes de países europeus como a Itália, a Bélgica e a Suíça. A disparidade da aplicação das teorias das imunidades jurisdicionais do Estado encadeou, inclusive, a negação de uma norma consuetudinária relativa à aplicação absoluta das imunidades jurisdicionais do Estado. Ver, entre outros, SALIBA, Aziz Tuffi. A imunidade absoluta de jurisdição de Estados: sólida regra costumeira" ou mito? Revista Brasileira de Direito Público, Belo Horizonte, v. 3, n. 8, p. 17-51, 2005. p. 21-23.

31 Vejam-se Allied Bank International v. Banco Crédito Agrícola (757 F.2d 516). UNITED STATES. Court of Appeals. Al- 
Diversos foram os desenrolares jurídicos, internos ou externos, que colaboraram, portanto, à proliferação da ação dos fundos "abutres" no cenário internacional. Os casos que envolveram a República da Costa Rica e o Banco Allied International, por exemplo, não só marcaram o âmbito das dívidas soberanas por caracterizar-se como um dos primeiros casos que envolveram a ação dos chamados hold-out creditors, mas, também, devido às suas decisões proferidas, pois o resultado dos julgamentos já apresentava em seu contexto alguns "incentivos" à aparição dos fundos "abutres".

Isso porque, embora, inicialmente, as decisões tenham acatado a invocação das defesas soberanas, o resultado do litígio, que começou a atrair a atenção da comunidade financeira de Nova York, colaborou, pelo contrário, à erosão da aplicação de doutrinas como a cortesia internacional e a doutrina do Ato do Estado. A linha de interpretação, que afirmou que a "recusa" à participação nas reestruturações soberanas representa um direito legítimo dos credores, solidificou-se nas decisões subsequentes às decisões dos litígios que envolveram o Banco Allied International. ${ }^{32}$ Essas decisões afirmaram, inclusive, que as pretensões desses credores e os meios por eles utilizados não afetavam a recuperação econômica dos Estados devedores.

Assim, além da clara evolução jurídica em favor dos fundos "abutres" nesses casos, essas decisões, também, podem ser vistas como uma defesa "moral" à atuação dos "abutres", uma vez que muitos argumentos atuais, que se mostram contrários a esta classe de investidores, afirmam que a recusa à participação destes fundos nas reestruturações soberanas acaba por dificultar a recuperação econômica dos Estados. As decisões proferidas no caso Allied e o reflexo das mesmas nos julgamen-

lied Bank International vs. Banco Credito Agricola. Setence March 18, 1985. Available at: <http://www.leagle.com/decision/198512737 57F2d516_11184/ALLIED\%20BANK\%20INTERN.\%20v.\%20 BANCO\%20CREDITO\%20AGRICOLA $>$. Accessed on: 16 dec. 2015; e CIBC Bank and Trust Co. (CAYMAN) Ltd v. Banco Central do Brasil (886 F. Supp. 1105), UNITED STATES. District Court. CIBC Bank and Trust co. vs. Banco Central do Brasil. Setence May 9, 1995. Available at: <http://www.leagle.com/decision/19951991 886FSupp1105_11830/CIBC $\% 20$ BANK $\% 20 \& \% 20$ TRUST $\% 20$ CO. $\% 20 \mathrm{v} . \% 20 \mathrm{BANCO} \% 20 \mathrm{CENT} \%$ 20do\%20BRASIL>. Accessed on: 16 dec. 2015.

32 Para uma descrição mais detalhada acerca das decisões subsequentes ao caso Allied, cfr., entre outros, FISCH, Jill; GENTILE, Caroline. Vultures or vanguards?: the role of litigation in sovereign debt restructuring. Emory Law Journal, Atlanta, v. 53, n. 1043, p. 1047-1116, 2004. p. 1085 e ss. tos subsequentes "incentivaram" a cultura dos fundos "abutres", que identificaram uma situação favorável à busca de lucros no mercado das dívidas soberanas internacionais.

\section{O PAPEL dOS FUNDOS ABUTRES NO CENÁRIO INTERNACIONAL}

O envolvimento desses fundos com o mercado das dívidas soberanas acarreta uma gama de consequências que vai além dos fatores econométricos envoltos nos processos internos. Já ultrapassamos o entendimento de que os Estados se identificavam como entidades autônomas, independentes e completas por si só. Pelo contrário, a evolução do conceito da soberania e os princípios presentes no modelo internacional pós-westfaliano destacam a subordinação dos Estados ao Direito Internacional e aos valores por ele empregados, como, por exemplo, o respeito aos direitos humanos. É por isso que se refuta, hoje, a ideia do Estado como entidade moral, caracterizando-o, longe disso, como um meio institucional que atende a um fim mais importante: a proteção dos direitos fundamentais dos seus cidadãos. ${ }^{33}$

O jogo especulativo dos fundos "abutres" envolve, pois, princípios e questões mais intrincadas do que aquelas vistas no cenário interno. A satisfação econômica desses fundos pode levar à negação de direitos básicos que deveriam ser assegurados a milhares de indivíduos. Em um país como a Zâmbia, por exemplo, em que a situação financeira é extremamente instável, a investida dos fundos "abutres" pode ser um obstáculo à melhoria do bem-estar da própria população. Em 2007, quando o governo da Zâmbia se encontrava sob as investidas desses fundos, o conselheiro presidencial e consultor da OXFAM, Martin Kalunga-Banda, relatou que o pagamento da dívida requerida pelos fundos "abutres" era equivalente ao custo do tratamento médico de mais de cem mil cidadãos. ${ }^{34}$

Não é de se estranhar, portanto, conforme já dito, que a atuação dos fundos abutres não foi bem recepcio-

33 Cfr MACHADO, Jónatas Eduardo Mendes. Direito internacional: do paradigma clássico ao pós-11 de setembro. 2. ed. Coimbra: Coimbra, 2004. p. 214.

34 O dinheiro cobrado pelos fundos "abutres", segundo o conselheiro presidencial, também se destinava à contratação de recursos humanos, como professores e enfermeiras, e à construção de infraestruturas básicas ao Estado. 
nada pela mídia e por diversos órgãos internacionais. ${ }^{35}$ Assim, a comunidade acadêmica vem apresentando diversas propostas que visam limitar, amplamente ou pontualmente, a atuação dos fundos abutres no cenário internacional. Essas propostas variam desde a inserção de cláusulas de ação coletiva (CAC) nos títulos de débito soberanos ${ }^{36}$ até a realização de lobbys de diversas ONG's, a fim de obter a aprovação de legislações internas voltadas à coibição da ação dos fundos de hedge nos tribunais nacionais. Essas propostas, por exemplo, encontraram aceitação por alguns políticos britânicos e norte-americanos, que propuseram, respectivamente, a legislação conhecida como "Developing Country Debt (Restriction of Recovery) Bill' e o projeto conhecido como "Stop 'Vulture' Funds Act" (Stop Very Unscrupulous Loan Transfers from Underprivileged Countries to Rich, Exploitive Funds $A c t)$.

É importante salientar, porém, que, em que pese a importância dessas legislações na defesa dos países pobres e altamente endividados, que normalmente são alvos dos fundos "abutres", muitas das propostas apresentadas pela comunidade internacional almejam coibir por completo a ação destes fundos no cenário internacional. Estas propostas não consideram, portanto, a importância que esses fundos podem ter no cenário das dívidas soberanas. Hoje já não é possível negar que, como fazem parte desse âmbito, esses fundos já apresentam papel no cenário das dívidas soberanas.

Contudo, para compreender o papel dos fundos "abutres" no âmbito das dívidas soberanas, faz-se importante, primeiramente, entender como funcionam as reestruturações dessas dívidas, uma vez que esse processo se apresenta como o único instituto que pode, em caso de real necessidade, ser benéfico a todas as partes envolvidas. Isso porque, diferentemente do que ocorre nos mercados econômicos internos, os Estados soberanos que não tem condições de pagar as suas dívidas só

35 Os fundos de investimento, por outro lado, rebatem as acusações e referem-se a si próprios por meio de termos neutros e, portanto, menos agressivos, afirmando, ao contrário, que os Estados devedores "são responsáveis pela erosão do sistema jurídico, devido ao seu desrespeito pelo Estado de Direito" e pela falta de pagamento de débitos legítimos. Cfr. BOSCO, David. The debt frenzy. Foreign Policy, Washington, n. 161, p. 36-42, July/Aug. 2007. p. 38-39. Veja-se DING, Yilin. Absolute, restrictive, or something more: did Beijing choose the right type of sovereign immunity for Hong Kong?. Emory International Law Review, Atlanta, v. 26, p. 997-1037, 2012. p. 1008. 36 Cfr. HASELER, Sonke. Collective action clauses in international sovereign contracts: whence the opposition?. Journal of Economic Surveys, New Jersey, v. 23, n. 5, p. 882-923, 2009. p. 885 e ss. podem recorrer a duas vias: a moratória ou a reestruturação das suas obrigações.

Não existe, portanto, um instituto de "falência" ao qual os Estados possam recorrer. ${ }^{37}$ Assim, o termo "reestruturação da dívida soberana" refere-se a "qualquer mudança realizada nos pagamentos previamente acordados, seja após a declaração de moratória ou, até mesmo, mediante a ameaça da falta de pagamentos". ${ }^{38}$ Desse modo, qualquer mudança nos acordos que regem o débito soberano pode ser considerada como uma reestruturação dos títulos desta dívida. Devido à falta de um instituto específico para reger esse processo, atualmente, embora diversos institutos de recuperação soberana tenham sido propostos, estas reestruturações ainda ocorrem de maneira "voluntária".39

Pode parecer ingênuo adjetivar essas reestruturações como "voluntárias", visto que nenhum investidor, em bom juízo ou de bom grado, acataria, voluntariamente, um corte de $70 \%$ no valor total dos seus créditos, fato que ocorreu, por exemplo, na recente reestruturação da dívida Grega. ${ }^{40}$ Faz-se importante, pois, esclarecer que essa voluntariedade, quando vinculada às reestruturações soberanas, somente expressa uma decisão que foi tomada em mútuo acordo das partes. ${ }^{41}$ Não significa dizer, pois, que os credores tenham poder suficiente para decidir, exclusivamente, acerca da concessão, ou não, da reestruturação das dívidas.

Assim, o sucesso das reestruturações dos débitos soberanos requer, muitas vezes, sacrifícios mútuos. ${ }^{42}$

37 BLACKMAN, Jonathan I.; MUKHI, Rahul. The evolution of modern sovereign debt litigation: vultures, alter egos, and other legal fauna. Law and Contemporany Problems, Durham, v. 73, p. 47-61, 2010. p. 48.

38 WAIBEL, Michael. Sovereign defaults before International courts and tribunals. Cambridge: Cambridge University, 2011. p. 14.

39 A expressão "reestruturação da dívida soberana" refere-se às mudanças realizadas em pagamentos previamente acordados. Estas mudanças podem ser realizadas após a moratória de um Estado ou mediante uma ameaça de moratória. WAIBEL, Michael. Sovereign defaults before international courts and tribunals. Cambridge: Cambridge University, 2011. p. 14.

40 GULATI, Mitu. Sovereign debt after 2013: things will never be the same again. Capital Markets Law Journal, Oxford v. 8, n. 2, p. 117-120, 2013. p. 117.

41 WAIBEL, Michael. Sovereign defaults before international courts and tribunals. Cambridge: Cambridge University, 2011. p. 14.

42 A crise de 1980, por exemplo, só pode ser resolvida devido ao reconhecimento, por parte dos bancos credores, da necessidade da realização de sacrifícios mútuos. POWER, Philip J. Sovereign debt: the rise of the secondary market and its implications for future restructurings. Fordham Law Review, New York, v. 64, n. 6, p. 20712077, Sept./Mar. 1996. p. 2705. 
Essas reestruturações, que têm por objetivo o remanejamento das obrigações estatais perante os credores, normalmente envolvem a elaboração de uma nova e, mais espaçada, agenda de pagamentos ou, sendo esta a opção mais buscada pelos devedores, a redução do valor total da dívida.

Os fundos "abutres", contudo, geralmente optam pela busca integral dos títulos por meio de ações judiciais. Diversos autores afirmam que a recusa apresentada pelos fundos "abutres" acaba por dissuadir a participação de outros credores na reestruturação voluntária apresentada pelos devedores. ${ }^{43}$

O caos causado por uma provável vitória judicial contra os países devedores pode dificultar ainda mais a reestruturação das dívidas ou, pior, danificar, severamente, a sua economia e suas futuras negociações. Isso porque, os demais credores podem, mediante uma ação judicial dos fundos "abutres", iniciar ações, a fim de salvar-se de mais prejuízos, seja vendendo seus títulos de débito no mercado secundário ou buscando também a via judiciária. ${ }^{44} \mathrm{~A}$ venda dos títulos de débito em plena crise e, por conseguinte, com baixos preços, pode piorar a situação financeira do devedor e, assim, a sua capacidade de pagar os seus débitos, uma vez que as vendas realizadas no mercado secundário, nesta determinada situação, refletem na credibilidade dos títulos e nas taxas de juros dos futuros empréstimos. ${ }^{45} \mathrm{~A}$ busca da cobrança pela via judicial, por outro lado, pode desencadear um efeito dominó, levando outros credores à provável alimentação deste ciclo vicioso.

Note-se, contudo, que muito embora esses fundos apresentem capacidade de disrupção nos processos de reestruturação das dívidas soberanas, não podemos negar as diversas teses que afirmam que a participação desses fundos no âmbito internacional pode sobrepujar o caos geralmente causado por estes nas reestruturações soberanas.

Alguns autores afirmam que, devido à sua preferên-

43 WHEELER, Christopher C.; ATTARAN, Amir. Declawing the vulture funds: rehabilitation of a comity defense in sovereign debt litigation. Stanford Journal of International Law, Stanford, v. 39, p. 253-284, 2003. p. 254.

44 NGUYEN, Davy V. H. Too big to fail? towards a sovereign bankruptcy regime. Cornell International Law Journal, New York, v. 45, n. 3, p. 697-723, 2012. p. 699.

45 NGUYEN, Davy V. H. Too big to fail? towards a sovereign bankruptcy regime. Cornell International Law Journal, New York, v. 45, n. 3, p. $697-723,2012$. p. 699. cia pela compra dos títulos de débito por meio dos mercados secundários, os fundos abutres acabam garantindo a liquidez dos mercados de débitos, apresentando-se como reguladores do mercado secundário. ${ }^{46}$

Outros autores afirmam que a presença dos fundos abutres no cenário internacional funciona como um contrapeso à falta de um instituto de falência específico nesse âmbito, garantindo que os Estados possam cancelar os pagamentos das obrigações previamente adquiridas, simplesmente por ser mais fácil escolher a moratória das suas dívidas em vez de empregar as medidas que seriam necessárias para continuar com os pagamentos acordados. ${ }^{47}$

Não há dúvida alguma de que a declaração de uma moratória soberana tem reflexos em diversos campos estatais, isto é, na política, na economia e, até mesmo, na reputação do Estado. Portanto, alguns autores defendiam a ideia de que as consequências políticas e econômicas da declaração de uma moratória eram suficientes, por si só, para coibir os Estados de declarar uma moratória "oportunista". ${ }^{48}$ Atualmente, porém, o entendimento parece ser outro. As consequências econômicas não são graves o suficiente para reprimir os opportunistic deffault's. O recente caso da Argentina comprova essa nova teoria. Tido por muitos como uma moratória oportunista, a República da Argentina vem sofrendo com a sua saga judicial com os fundos "abutres", uma vez que as consequências econômicas não parecem ter surtido efeito suficiente a ponto de refrear a moratória em primeiro lugar. ${ }^{49}$

Assim, se a ameaça das sanções ainda deve fazer-se presente no ambiente das dívidas soberanas, e as consequências econômicas que advêm da inadimplência de uma moratória não são suficientes para coibir a ação deliberada dos Estados, atualmente, a ameaça sancionatória deve ser aplicada pelos próprios credores. Di-

46 Cfr. WHEELER, Christopher C.; ATTARAN, Amir. Declawing the vulture funds: rehabilitation of a comity defense in sovereign debt litigation. Stanford Journal of International Law, Stanford, v. 39, p. 253-284, 2003. p. 254.

47 FISCH, Jill; GENTILE, Caroline. Vultures or vanguards?: the role of litigation in sovereign debt restructuring. Emory Law Journal, Atlanta, v. 53, n. 1043, p. 1047-1116, 2004. p. 1048.

48 NGUYEN, Davy V. H. Too big to fail? towards a sovereign bankruptcy regime. Cornell International Law Journal, New York, v. 45, n. 3, p. 697-723, 2012. p. 708-711.

49 Sobre este ponto, veja-se, inter alia, BAER, Werner Baer; MARGOT, Diego Margot; MONTES-ROJAS, Gabriel. Argentina's default and the lack of dire consequences. Economia Aplicada, Ribeirão Preto, v. 15, n. 1, p. 131-146, jan./mar. 2011. p. 137-140. 
ferentemente do passado, porém, os credores podem pressionar os Estados devedores por meio da utilização dos tribunais nacionais para buscar os seus direitos de cobrança. Nesse sentido, a presença dos "abutres" no cenário das dívidas soberanas poderia justificar-se, em caso de moratórias oportunistas, uma vez que esses fundos têm vasta experiência nestes litígios, bem como a possibilidade de lançar-se numa "saga" jurídica contra os soberanos, ao contrário dos outros credores privados individuais, que não teriam condições de suportar tamanha tarefa. Desse modo, a presença dos "abutres" se faria importante não só nos casos de moratórias oportunistas, mas, também, em casos nos quais as reestruturações sejam necessárias, porém apresentem termos extremamente prejudiciais às partes credoras minoritárias. ${ }^{50}$ Ademais, geralmente, os fundos "abutres" não estão sujeitos às pressões políticas dos Estados devedores e, inclusive, dos seus próprios Estados, tornando-os, assim, "livres" para litigar contra os devedores. ${ }^{51}$

Precisamos nos perguntar, porém, até que ponto a presença e a consequente ameaça desses fundos cumpre o objetivo que lhes é atribuído. Certamente, o pagamento que a Grécia realizou em benefício dos bold-out creditors demonstra que os Estados devedores estão cientes de que estes fundos, provavelmente, vão servir de balanço às moratórias ou reestruturações. Parece-nos, porém, que os devedores poderiam simplesmente pagar àqueles identificados como riscos à reestruturação. Nesse caso, somente os "abutres" lucrariam com a sua posição de vantagem perante os outros devedores.

Ademais, nessa situação, outros credores também seriam incentivados a segurar os seus créditos e não participar das reestruturações oferecidas, situação que poderia gerar, assim, uma disrupção desnecessária e encadear um efeito dominó nas reestruturações soberanas. Cabe salientar, também, que os fundos "abutres" ainda têm como objetivo principal a lucratividade em detrimento do desenvolvimento de alguns Estados. Com certeza a ação desses fundos não ficaria atrelada às moratórias oportunistas, pelo contrário, se incentivados, os fundos "abutres" passariam a negar a sua participação

50 Cfr. FISCH, Jill; GENTILE, Caroline. Vultures or vanguards?: the role of litigation in sovereign debt restructuring. Emory Law Journal, Atlanta, v. 53, n. 1043, p. 1047-1116, 2004. p. 1052, 1115.

51 Cfr BROOMFIELD, Elizabeth. Subduing the vultures: assessing government caps on recovery in sovereign debt litigation. Columbia Business Law Review, Washington, v. 2010, n. 2, p. 473-528, 2010. p. 514 em qualquer negociação, até mesmo naquelas realmente necessárias.

Outras bandeiras também têm sido levantadas em defesa da participação dos fundos "abutres" no âmbito das dívidas soberanas, nomeadamente com relação ao reflexo que as suas ações espargem no governo dos HIPC. Alguns autores afirmam que as ações desses fundos têm revelado grandes esquemas de corrupção nesses Estados. ${ }^{52} \mathrm{O}$ caso que se desenvolveu com base no litígio contra o Congo é um perfeito exemplo deste inusitado papel dos fundos "abutres". ${ }^{53} \mathrm{O}$ esquema, que envolvia, inclusive, funcionários de alto escalão do governo congolense - como, por exemplo, o presidente e o seu filho - nunca haveria de ser descoberto caso não fossem os vastos recursos investigativos do fundo "abutre".

$\mathrm{Na}$ tentativa de encontrar bens penhoráveis, que serviriam de garantia à sua ação judicial, o fundo "abutre" Elliott Associates acabou revelando esquema de corrupção estabelecido pelo governo do Congo, apontando mais de 82 mil dólares em fraudes. Segundo indícios revelados no caso, o governo congolense havia montado uma rede de empresas fictícias a fim de mascarar transações petrolíferas corruptas. Novamente, a "liberdade" política desses fundos apresentou-se como fator positivo no desempenho desse papel, uma vez que as autoridades locais não desvendariam as redes corruptas daquele país, especialmente devido à participação dos funcionários de alto escalão do governo.

Não podemos entrar em erro, neste artigo, e atribuir esses papéis aos fundos "abutres" sem analisar as consequências que estas atuações trazem ao âmbito das dívidas soberanas. Não cabe aqui, porém, analisar a razão pela qual os fundos realizam as suas investigações. O fato de a ação ser um meio ao fim lucrativo dos fundos não descaracteriza a consequência benéfica do

52 Veja-se BROOMFIELD, Elizabeth. Subduing the vultures: assessing government caps on recovery in sovereign debt litigation. Columbia Business Law Review, Washington, v. 2010, n. 2, p. 473-528, 2010. p. 516-517.

53 Na tentativa de encontrar bens penhoráveis, que serviriam de garantia à sua ação judicial, o fundo "abutre" Elliott Associates acabou revelando um esquema de corrupção estabelecido pelo governo do Congo, apontando mais de 82 mil dólares em fraudes. Segundo indícios revelados no caso, o governo congolense havia montado uma rede de empresas fictícias a fim de mascarar transações petrolíferas corruptas. AVERY, Ryan E. Out of the desert and to the oasis: legislation on predatory debt investing. University of Miami International and Comparative Law Review, Miami, v. 18, n. 2, p. 267-290, 2011. 
ato. Cabe aqui, porém, afirmar que muitas vezes os próprios fundos acabam gerando ações corruptas no meio do processo. Certamente, o litígio iniciado pelo fundo "abutre" Donegal teve o mérito de revelar o sistema corrupto anterior, porém, no decorrer deste processo, o próprio fundo de investimento, conforme indicam os autos, acabou utilizando processos corruptos para ter acesso aos títulos de débito soberanos. ${ }^{54}$

Conforme dissemos, não cabe desmerecer o ato benéfico realizado pelos fundos "abutres", mas não devemos esquecer, porém, que o retorno lucrativo é o primeiro e único objetivo desses fundos. A sua contribuição à transparência dos governos adquire natureza contraditória, portanto, quando os métodos empregados por esses fundos, desencadeiam corrupção ou estrago ainda maior para os Estados devedores. Ademais, segundo alguns autores, parece que as agências multinacionais cada vez mais estão voltadas a reduzir a corrupção nesses países altamente endividados. As organizações lideradas pelo Banco Mundial, FMI, por exemplo, têm implementado procedimentos destinados a aumentar a transparência das ações destes países. Não podemos negar que os fundos "abutres" chamaram a atenção para esses problemas e com isso os investidores retém os seus créditos, porém, devido ao estabelecimento dos programas de transparências destes órgãos internacionais, a corrupção poderá ser agora identificada durante as fases de reestruturação, seja com ou sem a participação dos fundos "abutres". ${ }^{55}$

54 Após a compra dos créditos da dívida externa zambiense, em 1999, o fundo abutre tentou entrar em negociações com o governo da Zâmbia. O fundo de investimento apresentou várias propostas de conversão da dívida que foram, incialmente, rejeitadas pela República da Zâmbia. Finalmente em 2003 o fundo abutre conseguiu realizar um acordo com o governo da Zâmbia. O acordo - que, segundo o governo da Zâmbia, havia sido confeccionado de maneira ilegal e por meios corruptos - foi essencial à estratégia do fundo Donegal. Isto porque, o acordo serviu para confirmar a validade da dívida do governo da Zâmbia perante o fundo e, mais importante, impediu que o governo da zambiense pudesse requerer o benefício da imunidade jurisdicional. O acordoprevia, expressamente, que "The Republic of Zambia irrevocably and unconditionally: (a) agrees that if Donegal brings proceedings against it or its assets in relation to this Agreement or the Debt, no immunity from those proceedings (including without limitation, suit, attachment prior to judgment, other attachment, the obtaining of judgment, execution or other enforcement) will be claimed by or on behalf of itself or with respect to its assets: (b) waives any such right of immunity which it or its assets now has or may subsequently acquire" Donegal International, Ltd. "Website do fundo de investimento Donegal.” Disponível em: <http:/ / www.donegalinternational.net/>. Acesso em: 21 ago. 2013.

55 Veja-se, neste sentido, AVERY, Ryan E. Out of the desert and to the oasis: legislation on predatory debt investing. University of $\mathrm{Mi}$ ami International and Comparative Law Review, Miami, v. 18, n. 2, p. 267-
Assim, não obstante os argumentos apresentados em prol da presença desses fundos no cenário internacional, a comunidade acadêmica continua a apresentar diversas propostas desenhadas, a fim de impedir a ação destes fundos no âmbito das dívidas soberanas, especialmente a fim de impedir a ação dos fundos "abutres" perante aqueles países que se encontram em situações extremamente críticas.

\section{A PERSONALIDADE JURÍDICA DOS FUNDOS ABU- TRES PERANTE O DIREITO INTERNACIONAL}

Muito embora algumas poucas normas e institutos do direito internacional geral tenham se desenvolvido nas últimas décadas, grande parte dos seus conceitos basilares clássicos não parecem ter acompanhado o mesmo rito evolucionário. Para alguns autores, por exemplo, são pessoas jurídicas de direito internacional público os Estados soberanos (aos quais se equiparam a Santa Sé) e as organizações internacionais em sentido estrito. Os primeiros sendo possuindo uma personalidade jurídica originária, enquanto os segundos possuem a personalidade derivada.

Não têm, portanto, para esses autores, personalidade jurídica os indivíduos, tampouco as empresas. Isso porque, segundo algumas teses, para que a ideia se torne científica, e não meramente "declamatória", seria necessário que os aspirantes a tal posição dispusessem, ao menos, "da prerrogativa ampla de reclamar, nos foros internacionais, a garantia de seu direito, e que tal qualidade resultasse de norma geral", e não de acordos tópicos do seu Estado pátrio com as cortes internacionais. ${ }^{56}$

Outros, contudo, afirmam, categoricamente, a consideração do indivíduo como unidade primaria e sujeito por excelência do direito internacional, observando, inclusive, à emergência de outros sujeitos internacionais, de natureza intergovernamental, supranacional, não governamental, bem como de sujeitos especiais, ou, ainda, atípicos. ${ }^{57}$

\section{0, 2011. p. 281-282.}

56 RESEK, Fransisco. Direito internacional público. 14. ed. São Paulo: Saraiva, 2013.

57 MACHADO, Jónatas Eduardo Mendes. Direito internacional: do paradigma clássico ao pós-11 de setembro. 2. ed. Coimbra: Coimbra, 2004; BROWNLIE, Ian. Principles of public international law. Oxford: Oxford University, 2003. p. 61-63. 
Assim, tendemos a refutar as extremas doutrinas clássicas, concordando com aquelas outras advindas da escola sociológica, defendendo, contudo, não somente a classificação dos indivíduos como sujeitos de direito internacional, mas sim a caracterização de outros entes que também podem assumir um papel de extrema importância no cenário internacional. Afinal, aqueles que podem ser considerados como membros da comunidade internacional, por serem destinatários diretos das suas normas, também o devem ser considerados como sujeitos de direito internacional. ${ }^{58}$ Ainda mais que, conforme refletido em um famoso dictum do Tribunal Internacional de Justiça, no parecer de Reparação dos prejuízos sofridos ao serviço das Nações Unidas, os sujeitos de direito, em um sistema jurídico, não necessariamente precisam ser idênticos quanto à sua natureza ou ao alcance dos seus direitos. Não existindo, assim, qualquer proibição quanto à coexistência de uma multiplicidade de sujeitos de direito internacional, que se distinguem por estatutos jurídicos diferentes e uma personalidade jurídica mais ou menos caracterizada. ${ }^{59}$ Por certo, não poderão ser, assim, considerados, contudo, de outra forma senão como pessoas jurídicas com personalidades derivadas.

As constantes tentativas de refrear a ação dos fundos abutres por meio de normas internacionais demonstram, claramente, a possibilidade de esses novos atores serem, direta e especificamente, afetados por normas internacionais, levando à crença de que esses atores poderão sim (se é que já não podem) ser considerados como sujeitos de direito internacional. Pesa, ainda, para a clara possibilidade, o fato de que esses atores, por vezes, e de certa forma, acabam garantindo, inclusive, o cumprimento das normas internacionais por parte dos Estados. Essas afirmações encontram respaldo, ainda, nas novas teses que vêm apontando uma drástica mudança nos paradigmas do direito internacional, ainda que estas ainda se encontrem em fase embrionária.

Essas novas teses afirmam que a globalização foi responsável por realocar os poderes político-econômicos, antes pertencentes somente aos Estados, entre os diversos atores do cenário internacional, levando ao entendimento de que, embora os argumentos da "mor-

58 PELLET, Alain; DINH, Nguyen Quoc; DAILLIER, Patrick. Direito internacional público. Lisboa: Calouste Gulbenkian, 2003. p. 412-413.

59 PELLET, Alain; DINH, Nguyen Quoc; DAILLIER, Patrick. Direito internacional público. Lisboa: Calouste Gulbenkian, 2003. p. 413 te" do Estado sejam exagerados, em alguns aspectos, a globalização enfraqueceu os Estados, deixando-os mais vulneráveis às forças globais. ${ }^{60}$

Sem dúvida, se analisarmos o comportamento do cenário internacional, nomeadamente na seara das dívidas soberanas, é possível afirmar os fundos "abutres" já passaram de meros coadjuvantes para atores principais, que hoje certamente se encontram sob os holofotes do cenário internacional. Sem dúvida, se os Estados realmente estão sendo enfraquecidos pelo processo de globalização, também é possível afirmar que outros atores estão prontos para preencher essa lacuna de poder, explorando e moldando as relações internacionais por meio do exercício da sua influência em situações oportunistas. ${ }^{61}$

A erosão dos institutos jurídicos que protegiam a soberania dos Estados, em muito acelerada devido às decisões políticas passadas, e o estabelecimento das condições econômicas ideais para a proliferação dos fundos "abutres" demonstram, claramente, embora em um âmbito limitado, a verificação da tendência da mudança do paradigma internacional já defendido por alguns autores.

Se acatarmos como verdadeira essa linha interpretativa que afirma a mudança do paradigma jurídico internacional que tem o Estado como objeto central para um paradigma que coloca ao centro as entidades corporativas, podemos afirmar que a presença e a proliferação dos fundos "abutres" no cenário internacional deixam de ser resultado de uma descompassada evolução entre o cenário econômico e o cenário político-jurídico, passando a ser, na verdade, um sinal da tendência que está a se instaurar no cenário internacional. Certamente, a coibição da atuação desses fundos, nesse cenário, pode tornar-se mais complicada.

\section{Considerações finais}

Em suma, no mínimo, devemos admitir que os fundos "abutres" já protagonizam papel de destaque no

60 Cfr GARCIA, Frank J. Globalization, power, states, and the role of law. Boston College Law Review, Boston, v. 54, n. 3, p. 903-919, 2013. p. 903.

61 GARCIA, Frank J. Globalization, power, states, and the role of law. Boston College Law Review, Boston, v. 54, n. 3, p. 903-919, 2013. p. 911. 
âmbito das dívidas soberanas, possuindo, caso a caso, e com algumas ressalvas, importante papel no cenário das dívidas soberanas. A afirmação categórica da sua personalidade jurídica, contudo, ainda não encontra respaldo nos clássicos conceitos jusinternacionalistas, o que, tendo em vista as constantes mudanças trazidas pelo novo cenário internacional globalizado, não nos parecem obstáculo à sua caracterização como tal em um futuro extremamente próximo, se não já presente.

\section{REFERÊNCIAS}

ALMEIDA, Francisco Ferreira de. Direito internacional público. 2. ed. Coimbra: Coimbra, 2003.

AREWA, Olufunmilayo B. Vultures, hyenas, and african debt: private equity and Zambia. Northwestern Journal of International Law and Business, Chicago, v. 29, n. 3, p. 643674, July/Sept. 2009.

AVERY, Ryan E. Out of the desert and to the oasis: legislation on predatory debt investing. University of Miami International and Comparative Law Review, Miami, v. 18, n. 2, p. 267-290, 2011.

BAER, Werner Baer; MARGOT, Diego Margot; MONTES-ROJAS, Gabriel. Argentina's default and the lack of dire consequences. Economia Aplicada, Ribeirão Preto, v. 15, n. 1, p. 131-146, jan./mar. 2011.

BLACKMAN, Jonathan I.; MUKHI, Rahul. The evolution of modern sovereign debt litigation: vultures, alter egos, and other legal fauna. Law and Contemporany Problems, Durham, v. 73, p. 47-61, 2010.

BOSCO, David. The debt frenzy. Foreign Policy, Washington, n. 161, p. 36-42, July/Aug. 2007.

BRASIL. Ministério das Relações Exteriores. Comunicado Conjunto dos Presidentes dos Estados Partes do Mercosul. Disponível em: <http://www.itamaraty.gov.br/ index.php?option $=$ com_content\&view $=$ article\&id $=3$ 250:comunicado-conjunto-dos-presidentes-dos-estados-partes-do-mercosul-brasilia-7-de-dezembro-de$2012 \&$ catid $=42 \&$ lang $=p t-B R \& I t e m i d=280>$. Acesso em: 15 dez. 2015.

BRITO, Wladmir. Direito internacional público. Coimbra: Coimbra, 2008.

BROOMFIELD, Elizabeth. Subduing the vultures: as- sessing government caps on recovery in sovereign debt litigation. Columbia Business Law Review, Washington, v. 2010, n. 2, p. 473-528, 2010.

BROWNLIE, Ian. Principles of public international law. Oxford: Oxford University, 2003.

CARSON, Scott Alan. Vulture investors, predators of the 90s: an ethical examination. Journal of Business Ethics, Berlin, v. 17, n. 5, p. 543-555, 1998.

CARVALHO, Geraldes de. Da imunidade jurisdicional dos Estados estrangeiros. Colectânea de Jurisprudência, v. 10, n. 4, p. 33-37, 1985.

CASSESE, Antonio. International law in a divided world. Oxford: Clarendon, 1986.

DING, Yilin. Absolute, restrictive, or something more: did Beijing choose the right type of sovereign immunity for Hong Kong?. Emory International Law Review, Atlanta, v. 26, p. 997-1037, 2012.

DOLINGER, Jacob. A imunidade jurisdicional dos Estados. Revista de Informação Legislativa, Brasília, v. 19, n. 76, p. 5-64, 1982.

EDWARDS, Sebastian. Crisis and reform in Latin America: from despair to hope. New York: Oxford University, 1995.

FISCH, Jill; GENTILE, Caroline. Vultures or vanguards?: the role of litigation in sovereign debt restructuring. Emory Law Journal, Atlanta, v. 53, n. 1043, p. 1047-1116, 2004.

FUNG, William; HSIEH, David A. Empirical characteristics of dynamic trading strategies: the case of hedge funds. Review of Financial Studies, Oxford, v. 10, n. 2, p. 75-302, 1997.

GARCIA, Frank J. Globalization, power, states, and the role of law. Boston College Law Review, Boston, v. 54, n. 3, p. 903-919, 2013.

GOLDMAN, Samuel E. Mavericks in the market: the emerging problem of hold-outs in sovereign debt restructuring. UCLA Journal of International Law and Foreign Affairs, California v. 5, p. 159-197, 2000.

GOREN, Jonathan. State-to-State debts: sovereign immunity and the "vulture" hunt. The George Washington International Law Review, Washington, v. 41, n. 3, p. 681708, 2010.

GULATI, Mitu. Sovereign debt after 2013: things will never be the same again. Capital Markets Law Journal, 
Oxford v. 8, n. 2, p. 117-120, 2013.

HASELER, Sonke. Collective action clauses in international sovereign contracts: whence the opposition?. Journal of Economic Surveys, New Jersey, v. 23, n. 5, p. 882 923, 2009.

HAYS II, James M. The sovereign debt dilemma. Brooklyn Law Review, New York, v. 75, n. 3, p. 905-933, 2010.

HURLEY, Gail. Taming the vultures: are new measures enough to protect debt relief gains? Belgiui: Eurodad, dez. 2008. Available at: <http://eurodad.org/uploadedfiles/whats_new/reports/the $\% 20$ rise $\% 20$ of $\% 20$ the $\% 20$ vulture $\% 20$ layout.pdf $>$. Accessed on: $16 \mathrm{dec}$. 2015.

LHABITANT, François-Serge. Handbook of hedge funds. England: J. W. and Sons, 2011.

LO, Andrew W. Risk management for hedge funds: introduction and overview. Financial Analysts Journal, Stanford, v. 57, n. 6, p. 16-33, Nov./Dec. 2001.

MACHADO, Jónatas Eduardo Mendes. Direito internacional: do paradigma clássico ao pós-11 de setembro. 2. ed. Coimbra: Coimbra, 2004.

MADRUGA FILHO, Antenor Pereira. A renúncia à imunidade de jurisdição pelo estado brasileiro e o novo direito da imunidade de jurisdição. São Paulo: Renovar, 2003.

MONTELEONE, Theresa A. A vulture's gamble: high-stakes interpretation of sovereign debt contracts in NML Capital, Ltd v Republic of Argentina. Capital Markets Law Journal, Oxford, v. 8, n. 2, p. 149-165, 2013.

NGUYEN, Davy V. H. Too big to fail? towards a sovereign bankruptcy regime. Cornell International Law Journal, New York, v. 45, n. 3, p. 697-723, 2012.

PELLET, Alain; DINH, Nguyen Quoc; DAILLIER, Patrick. Direito internacional público. Lisboa: Calouste Gulbenkian, 2003.

POWER, Philip J. Sovereign debt: the rise of the secondary market and its implications for future restructurings. Fordham Law Review, New York, v. 64, n. 6, p. 2071-2077, Sept./Mar. 1996.

PROCTOR, Charles. Vulture funds and sovereign debt: the zambian experience. Journal of South African Law, Philadelphia, n. 4, p. 629-641, 2007.

RESEK, Fransisco. Direito internacional público. 14. ed. São Paulo: Saraiva, 2013.
SALIBA, Aziz Tuffi. A imunidade absoluta de jurisdição de Estados: sólida regra costumeira ou mito? Revista Brasileira de Direito Público, Belo Horizonte, v. 3, n. 8, p. 17-51, 2005.

SCHUMACHER, Julian; TREBESCH, Christoph; ENDERLEIN, Henrik. Sovereign defaults in court: the rise of creditor litigation 1976-2010. Social Science Research Network, June 2013. Available at: <http://www.scu. edu/business/economics/upload/SovereignDefaultsinCourt.pdf>. Accessed on: 16 dec. 2015.

SHAW, Malcolm N. International law. 6. ed. Cambridge: Cambridge University, 2008.

SILVA, Alexandre Pereira da; PEREIRA, Mariana Yante Barrêto. "Fundos abutres" vs. Estados nacionais: soberania e atuação do Tribunal Internacional do Direito do Mar a partir do caso da fragata libertad. Revista de Direito Internacional, Brasília, v. 10, n. 1, 2013.

SOOKUN, Devi. Stop vulture fund lawsuits: a handbook. London: Commonwealth Secretariat, 2010.

UNITED STATES. Court of Appeals. Allied Bank International vs. Banco Credito Agrícola. Setence March 18, 1985. Available at: <http://www.leagle.com/decision/ 19851273757F2d516_11184/ALLIED\%20BANK\%20 INTERN.\%20v.\%20BANCO \%20CREDITO \%20 AGRICOLA>. Accessed on: 16 dec. 2015.

UNITED STATES. District Court. CIBC Bank and Trust co. vs. Banco Central do Brasil. Setence May 9, 1995. Available at: <http://www.leagle.com/decision/1995199 1886FSupp1105_11830/CIBC\%20BANK\%20\&\%20 TRUST\%20CO.\%20v.\%20BANCO $\% 20$ CENT. $\% 20$ do\%20BRASIL>. Accessed on: 16 dec. 2015.

WAIBEL, Michael. Sovereign defaults before international courts and tribunals. Cambridge: Cambridge University, 2011.

WEI, Jiang; KAI, Li; WEI, Wang. Hedge funds and chapter 11. The Journal of Finance, v. 67, n. 2, p. 513-559, 2012.

WHEELER, Christopher C.; ATTARAN, Amir. Declawing the vulture funds: rehabilitation of a comity defense in sovereign debt litigation. Stanford Journal of International Law, Stanford, v. 39, p. 253-284, 2003.

WOLLASTON, Andrew. The growing importance of debt in european corporate transactions. Insolvency Intelligence, London, v. 18, n. 10, p. 145-149, 2005. 
YAP, Suniati. Investing in chapter 11 companies: vultures or white knights?. Southewestern Journal of Law and Trade in the Americas, California, v. 2, p. 153-174, Mar./ Apr. 1995.
ZAMBIA loses 'vulture fund' case. BBC News, London, Feb 15, 2007. Available at: <http://www.scu.edu/business/economics/upload/SovereignDefaultsinCourt. pdf $>$. Accessed on: 16 dec. 2015. 
Para publicar na Revista de Direito Internacional, acesse o endereço eletrônico www.rdi.uniceub.br ou www.brazilianjournal.org.

Observe as normas de publicação, para facilitar e agilizar o trabalho de edição. 